\title{
Theoretical Study of Thermal Cracking For Acenaphthylene Molecule
}

\author{
Muthana A. Shanshal * \\ Qhatan A.Yousif **
}

Received 18, October, 2012

Accepted 5, December, 2012

\begin{abstract}
Density Functional Theory (DFT) calculations were carried out to study the thermal cracking for acenaphthylene molecule to estimate the bond energies for breaking C8b-C5a, C5a-C5 , C5-C4, and C5-H5 bonds as well as the activation energies. It was found that for $\mathrm{C} 8 \mathrm{~b}-\mathrm{C} 5 \mathrm{a}, \mathrm{C} 5-\mathrm{C} 4$, and $\mathrm{C} 5-\mathrm{H} 5$ reactions it is often possible to identify one pathway for bond breakage through the singlet or triplet states. The atomic charges, dipole moment and nuclear - nuclear repulsion energy supported the breakage bond.Also, it was found that the activation energy value for $\mathrm{C} 5-\mathrm{H} 5$ bond breakage is lower than that required for C8b-C5a , C5a-C5 , C5-C4 bonds which refer to $\mathrm{C} 5-\mathrm{H} 5$ bond in acenaphthylene molecule are weaker than $\mathrm{C} 8 \mathrm{~b}$ C5a , C5a-C5 , C5-C4 bonds .It is reasonable to presume that C5-H5 bonds are broken first when a acenaphthylene molecule is exposed to thermal cracking. It seems that the characteristic planarity for the polyaromatic hydrocarbons is an important factor to acquire the molecule structure of the required stability along the reaction path . The trends in the bond energies and the configuration structures are discussed .
\end{abstract}

Keywords: C-H rupture and C-C rupture, DFT calculations, thermal cracking, acenaphthylene

\section{Introduction:}

Aromatic compounds are present in high concentrations in crude oil and composited about $3-4 \%$ of the heavy crude oil $^{(1)}$. The term cracking applies to the decomposition of petroleum whereby the higher molecular weight constituents of petroleum are converted to low molecular weight products $^{(2)}$. Cracking reactions involve carbon-carbon and carbon-hydrogen bonds rupture ${ }^{(3)}$. Bond dissociation energy is recognized as a measure of bond strength and it is widely utilized for estimating the heats of formation in organic chemistry $^{(4-5)}$. It is not easy to determine the carbon - carbon and carbon - hydrogen bonds dissociation energies of polyaromatic hydrocarbon experimentally. Thus, the computational chemistry has made impressive advances in the calculation

of highly accurate bond energies ${ }^{(6)}$. For this purpose the present study is devoted to determinate the bond energies of some important bonds in acenaphthylene molecule such as the $\mathrm{C} 8 \mathrm{~b}-\mathrm{C} 5 \mathrm{a}, \mathrm{C} 5 \mathrm{a}-\mathrm{C} 5$, C5-C4 , and C5$\mathrm{H} 5$ as well as estimate the values of the atomic charges, dipole moment, and nuclear-nuclear repulsion energy by Density Functional Theory .

\section{Materials and Methods:}

Quantum chemical calculations employing $\mathrm{DFT}^{(7)}$ are carried out to investigate the energies of breakage the C8b-C5a , C5a-C5 , C5-C4, and C5-H5 bonds. All calculations are conducted using the Gaussian ${ }^{(8)} 2009$ suite programs in the workstation that have high performance in the CPU process and memory size . DFT allows to compute all properties of systems by the electron

\footnotetext{
*Department of chemistry, College of Science , Baghdad University /Baghdad/ Iraq

**Department of chemistry, College of Science, Al-Qadissya University / Iraq
} 
density,$\rho(r)$ which is a function of three variables,$\rho(r)=f(x, y, z)$. The hybrid DFT method included a mixture of Hartree - Fock exchange with DFT exchange correlation. Also, this meted is known as hyper - GGA functional ${ }^{(9)}$. The most popular hybrid functional is known B3LYB and was suggested by Stephenes. In B3LYP , the PWal correlation functional is replaced by the LYP functional. B3 ( Becke three parameter hybrid functionals, these functionals have the form devised by Becke, LYP is the Lee - Yang - Parr correlation functional $^{(9,10)}$. Recent work has suggested that B3LYP approach is the best functional for the calculation of hydrocarbon bond energies ${ }^{(6,11)}$. Significant improvement in the agreement between electronic structure calculations and experiment can be achieved by increasing the number of basis set functions . Thus, the triple - zeta (TZ) basis set such as $6-311 \mathrm{G}^{(9,12)}$ used in the present work are in conformity with $\mathrm{UHF}^{(11)}$. Initially, the optimization energy procedure has been carried out to calculate the energy bond for the original state " equilibrium state ". Thereafter, changed the distance between the atoms that under study C8b-C5a, C5a-C5 , C5$\mathrm{C} 4$, and $\mathrm{C} 5-\mathrm{H} 5$ bonds and calculate the values of the atomic charges, dipole moment, and nuclear-nuclear repulsion energy.

\section{Results and Discussion :}

The energies required to break C5-H5 and C8b-C5a, C5a-C5, and $\mathrm{C} 5-\mathrm{C} 4$ bonds have been calculated by virtue of the singlet and triplet states . By examining the potential energy curves, one can deduce whether a particular reaction pathway for bond breakage is favoured in comparison with other pathways. However, for the $\mathrm{C} 5-\mathrm{H} 5$ and $\mathrm{C} 8 \mathrm{~b}-\mathrm{C} 5 \mathrm{a}$, and $\mathrm{C} 5-\mathrm{C} 4$ reactions, it is often possible to identify one pathway for bond breakage through the singlet or triplet states by using density functional theory (DFT). The carbon and hydrogen atoms of the acenaphthylene molecule are numbered in conformity with the convention laid down by the International Union of Pure and Applied Chemistry (IUPAC) ${ }^{(13)}$ for the regular naming of chemical compounds (scheme 1). Furthermore, Scheme 1 displays the

atomic charges for each of the atoms by means of various colours denoting -

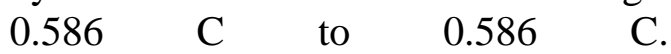

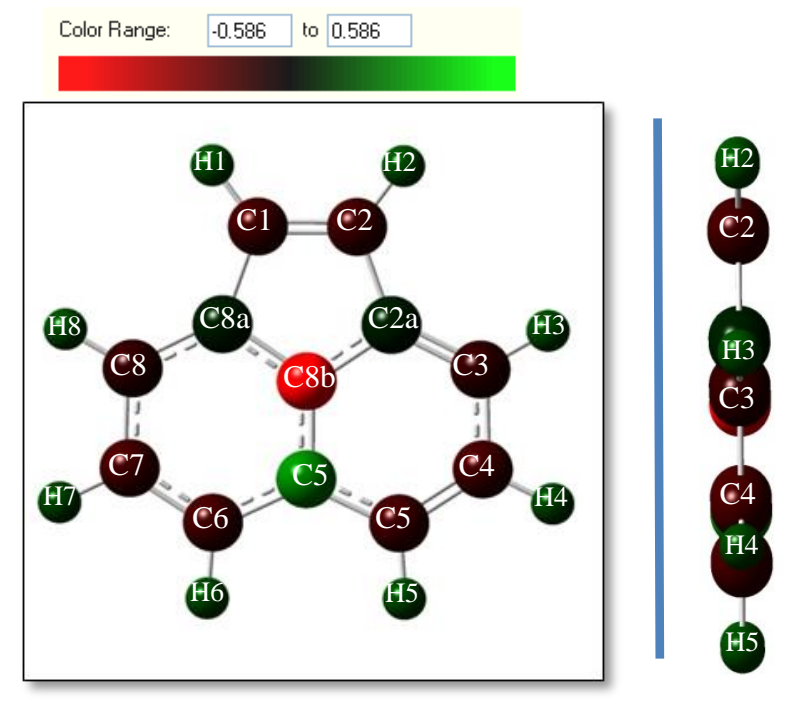

Scheme (1): Shows the configuration of acenaphthylene molecule with compatibility of atomic charges . 
From the results presented in Table (1) and Figure (1), it is notable that the values of the activation energy $(236.2514 \mathrm{kCal} / \mathrm{mole})$ and the reaction energy $(192.7554 \mathrm{kcal} / \mathrm{mol})$ in the singlet state at the bond lengths $3.6 \AA$ and $3.7 \AA$ respectively. The pictorial representation (2) depicts the transition state and the product of the cleavage of the C8b-C5a bond and the atomic charges for each the atoms are indicated by means of a coloured key . The transition state clearly forms the allene fragments and in which all the atoms reach a stable octet ${ }^{(14)}$ (the atom $\mathrm{C} 8 \mathrm{a}$ is central to one allene and the atom $\mathrm{C} 5 \mathrm{a}$ is central to the other), causing the molecular structure to pucker and in turn lose planarity. Additionally at a bond length of $3.7 \AA$, the same changes occur (in one pure allene fragment) albeit in a transition state that is more distorted ; thus, the two configurations may be unstable. Table (1) and Figures (2-4) confirm the cleavage of the C8b-C5a bond at a bond length of $3.7 \AA$. Table (1) and Figure (2) illustrate the discernible change in the atomic charges in comparison with ground state (scheme $1)$.

Table (1): Shows the bonds lengths for acenaphthylene molecule in Angstrom units and the bond energies in kilocalories per mole as well the values of the nuclear-nuclear repulsion energy, atomic charges and dipole moment for $\mathbf{C 8 b}$ C5a bond breakage of acenaphthylene molecule .

\begin{tabular}{|c|c|c|c|c|c|c|}
\hline $\begin{array}{r}\text { Bond } \\
\text { lengthÅ }\end{array}$ & $\mathbf{E}(\mathbf{a} . \mathbf{u})$ & $\Delta \mathrm{E}(\mathrm{kCal} / \mathrm{mol})$ & $\begin{array}{c}\text { Dipole } \\
\text { moment(Debye) }\end{array}$ & $\begin{array}{c}\mathrm{E}_{\mathrm{N}-\mathrm{N}}(\text { Hartree) } \\
\times 10^{+2}\end{array}$ & $\begin{array}{c}\text { Atomic } \\
\text { charge } \underline{\mathrm{C} 8 \mathrm{~b}}\end{array}$ & $\begin{array}{c}\text { Atomic } \\
\text { charge C5a }\end{array}$ \\
\hline 1.16 & -462.0043783 & 43.13422 & 0.2017 & 6.173292584785 & -0.720116 & 0.325878 \\
\hline 1.36 org. & -462.0731170 & 0.000000 & 0.3787 & 6.110724998616 & -0.613214 & 0.289163 \\
\hline 1.6 & -462.0510408 & 13.85304 & 0.5167 & 6.038283407198 & -0.422749 & 0.225062 \\
\hline 1.8 & -462.0062141 & 41.98224 & 0.5742 & 5.982035672295 & -0.276473 & 0.157775 \\
\hline 2 & -461.9569060 & 72.92356 & 0.5998 & 5.929470450631 & -0.176033 & 0.090398 \\
\hline 2.2 & -461.9089440 & 103.0202 & 0.6101 & 5.881783156769 & -0.124183 & 0.031885 \\
\hline 2.4 & -461.8642531 & 131.0642 & 0.6079 & 5.839246670431 & -0.108800 & -0.012496 \\
\hline 2.6 & -461.8352348 & 149.2735 & 2.1559 & 5.859330048654 & -0.072022 & -0.065198 \\
\hline 2.8 & -461.8140607 & 162.5604 & 1.6577 & 5.882769160226 & -0.020047 & -0.082308 \\
\hline 2.9 & -461.8080144 & 166.3546 & 1.5311 & 5.876765458025 & -0.000734 & -0.052324 \\
\hline 3 & -461.8023077 & 169.9355 & 1.5225 & 5.867451914201 & 0.014289 & -0.032521 \\
\hline 3.2 & -461.7459833 & 205.2797 & 2.1761 & 5.745140326481 & -0.224555 & -0.020380 \\
\hline 3.4 & -461.7225141 & 220.0068 & 0.5964 & 5.727134353308 & -0.114848 & 0.034182 \\
\hline 3.6 T.S. & -461.6966268 & 236.2514 & 1.0730 & 5.694984494939 & -0.104368 & 0.047518 \\
\hline 3.7 & -461.7659419 & 192.7554 & 1.8396 & 5.925183527237 & 0.093743 & 0.008031 \\
\hline 3.8 & -461.7611465 & 195.7646 & 1.8421 & 5.928462892786 & 0.091720 & 0.018111 \\
\hline 4 & -461.7499731 & 202.7760 & 1.8585 & 5.931965043623 & 0.087208 & 0.037093 \\
\hline 4.2 & -461.7363883 & 211.3006 & 1.8836 & 5.931480286944 & 0.084515 & 0.051213 \\
\hline 4.4 & -461.7199075 & 221.6425 & 1.9075 & 5.928640834872 & 0.083144 & 0.058612 \\
\hline
\end{tabular}




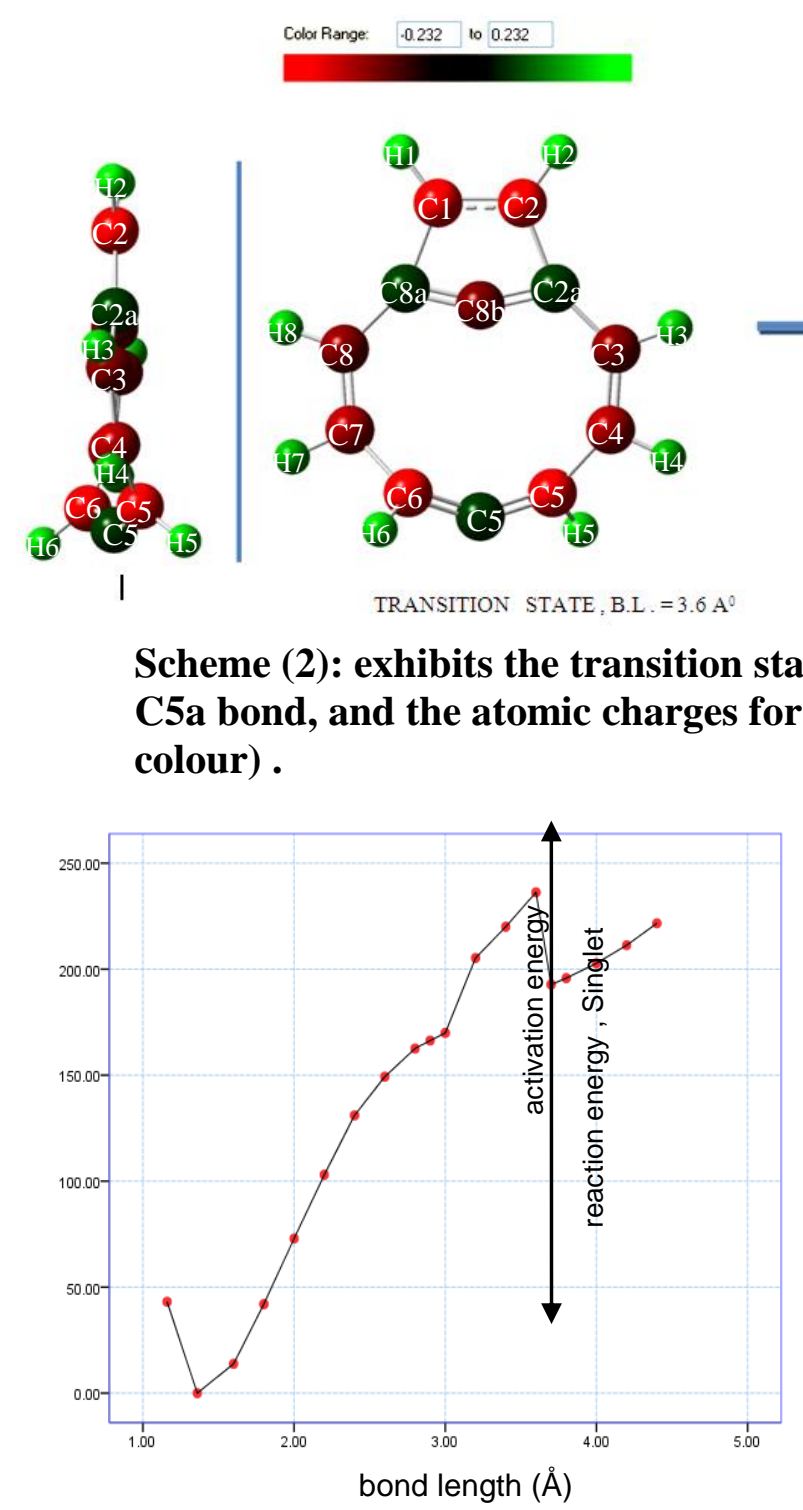

Fig (1): Shows the potential energy curve for acenaphthylene molecule for C8b-C5a bond breakage .

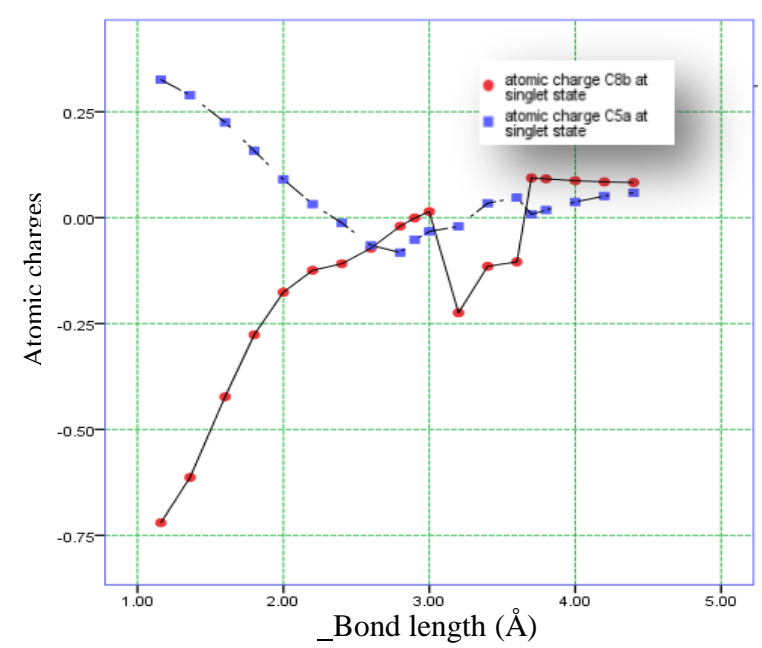

Fig (3): shows the atomic charges for $\mathrm{C} 8 \mathrm{~b}$ and C5a to acenaphthylene molecule . colour) .
Color Range: $\quad .0230 \quad$ to 0.230

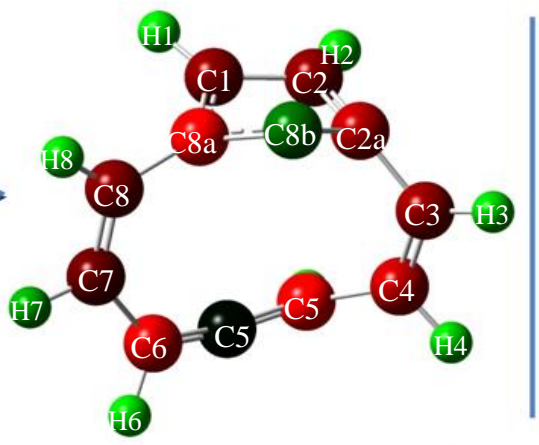

SINGLET BRAKAGE, B.L $=3.7 \mathrm{~A}^{0}$

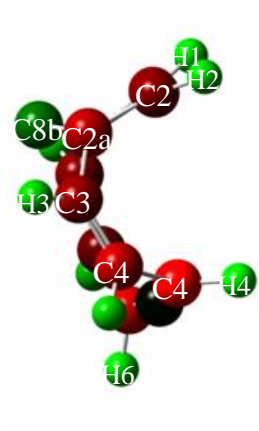

of the C8bC5a bond, and the atomic charges for each the atoms (distinguished by means of

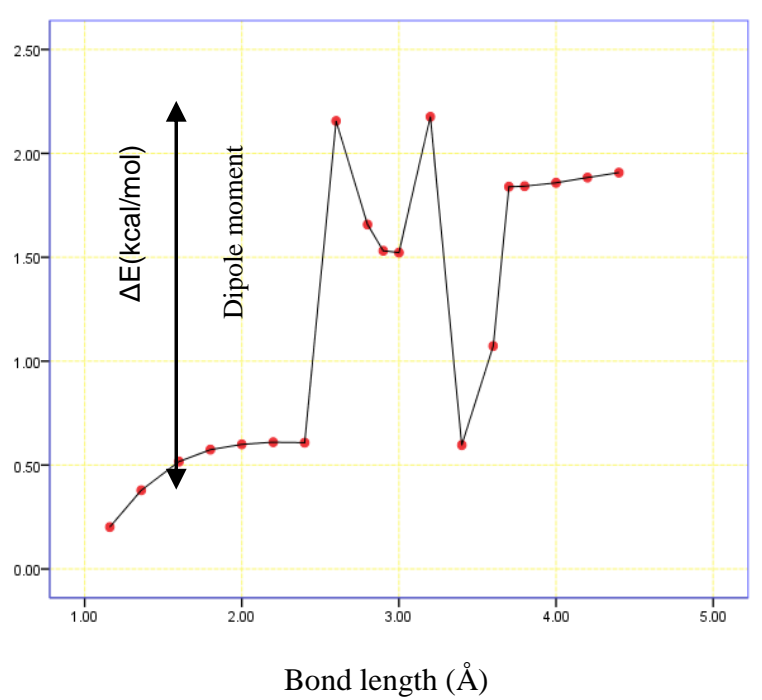

Fig (2): shows the dipole moment for $\mathrm{C} 8 \mathrm{~b}$ and $\mathrm{C} 5 \mathrm{a}$ to acenaphthylene molecule.

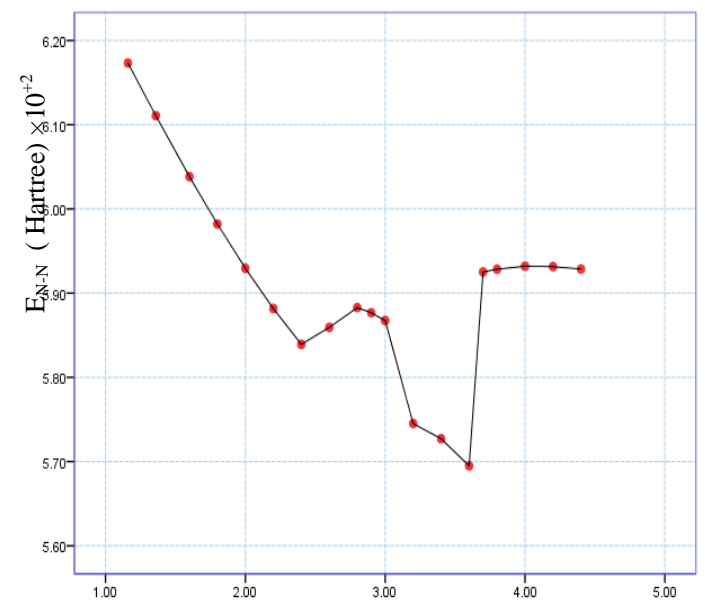

Fig (4): shows the $\mathrm{E}_{\mathrm{N}-\mathrm{N}}$ ( Hartree) for $\mathrm{C} 8 \mathrm{~b}$ and C5a to acenaphthylene molecule . 
The C5a-C5 bond ruptures at a bond length of $3.9 \AA$ in both triplet and singlet states, and the latest state is more stable because of the $E_{r}$ for the pathway of reaction energy is lower (Figure 5). Scheme (3) represents the mechanism of bond breakage $\mathrm{C} 5 \mathrm{a}-\mathrm{C} 5$ at a bond length of $3.9 \AA$ in singlet and triplet states, in addition to the spatial geometrical structure of transition state at a bond length of $3.8 \AA$ and the atomic charges for all atoms in the molecule. In the transition state, the configuration of the open hydrocarbon chain contains both double and single bonds as well as the allene fragment, without loss of the planarity. The configuration of the allene fragments (the atom C5a is central to one allene and the atom $\mathrm{C} 5$ is central of the other) retains the electronic spin, while the hydrogen atom $(\mathrm{H} 4)$ is transferred to the carbon atom (C5). In doing so, all the atoms in the molecule reach a stable electronic octet (14) and accomplish the required stability. This modification in geometrical structure is unnoticeable in the triplet state. Furthermore, the data presented in Figures(6-9) support the cleavage of the C5a-C5a bond at the aforementioned bond length .

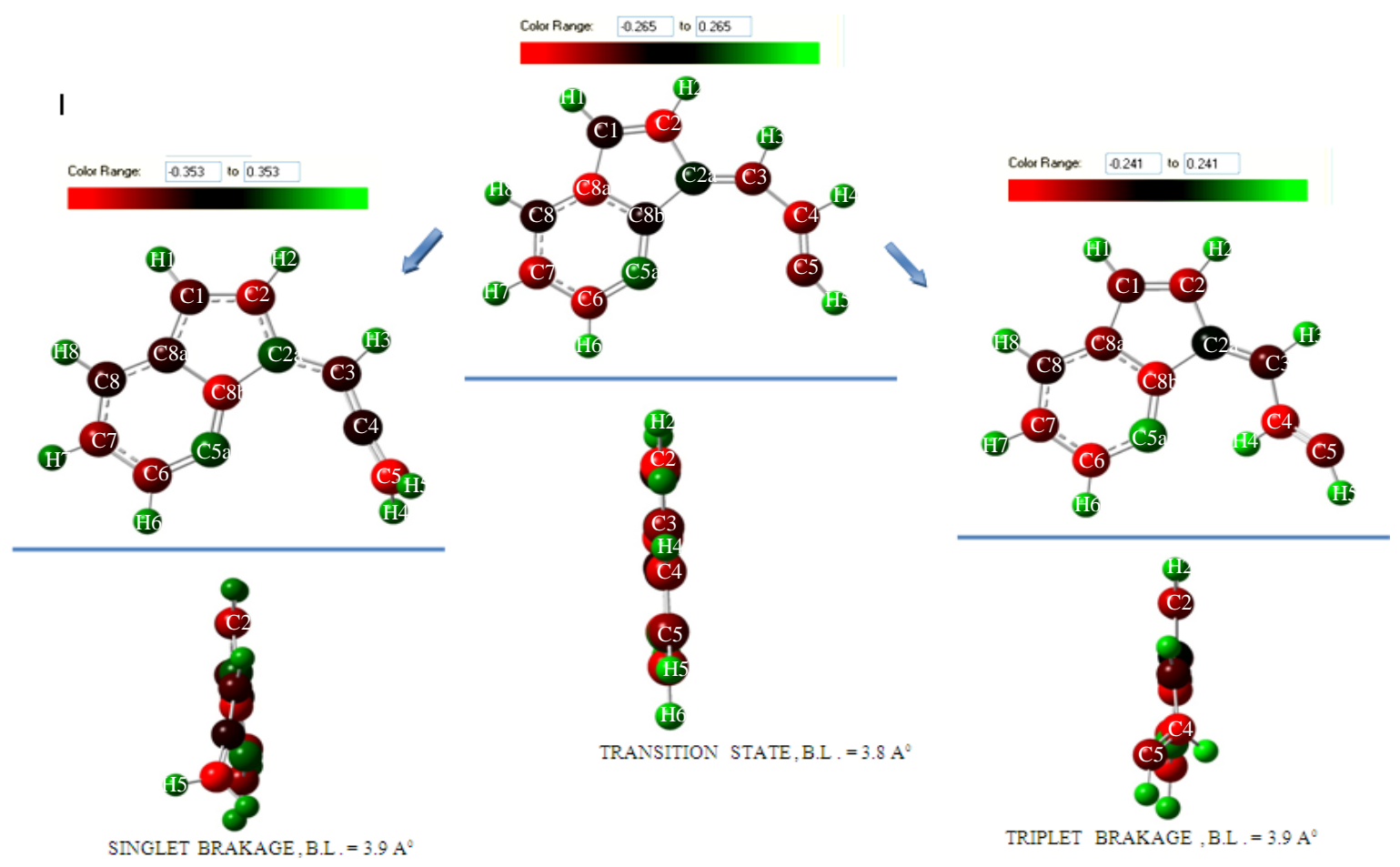

Scheme (3): exhibits the transition state, the product of the cleavage of the C5a$\mathrm{C} 5$ bond, and the atomic charges for each the atoms (distinguished by means of colour) . 


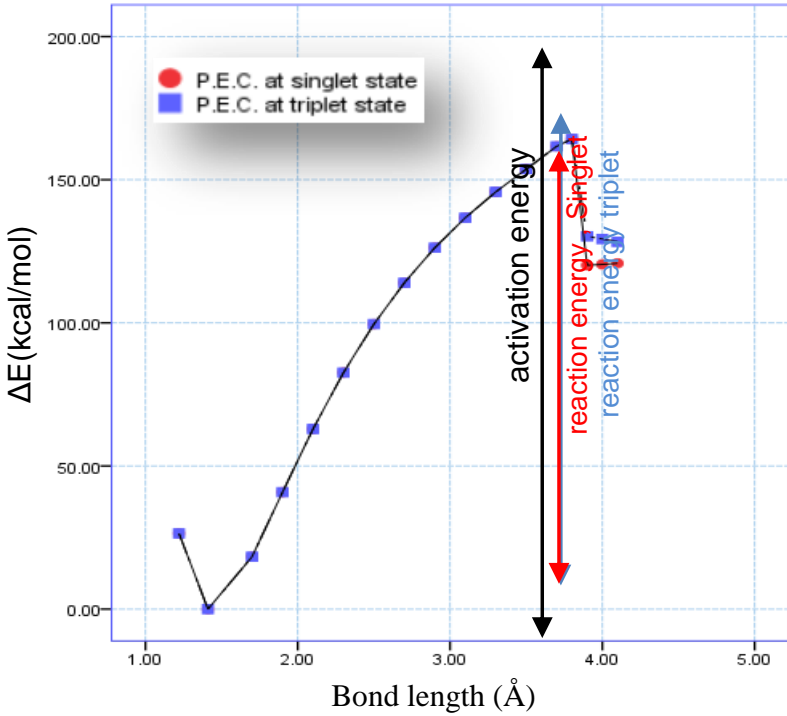

Fig (5): Shows the potential energy curve for acenaphthylene molecule for C5a-C5 bond breakage .

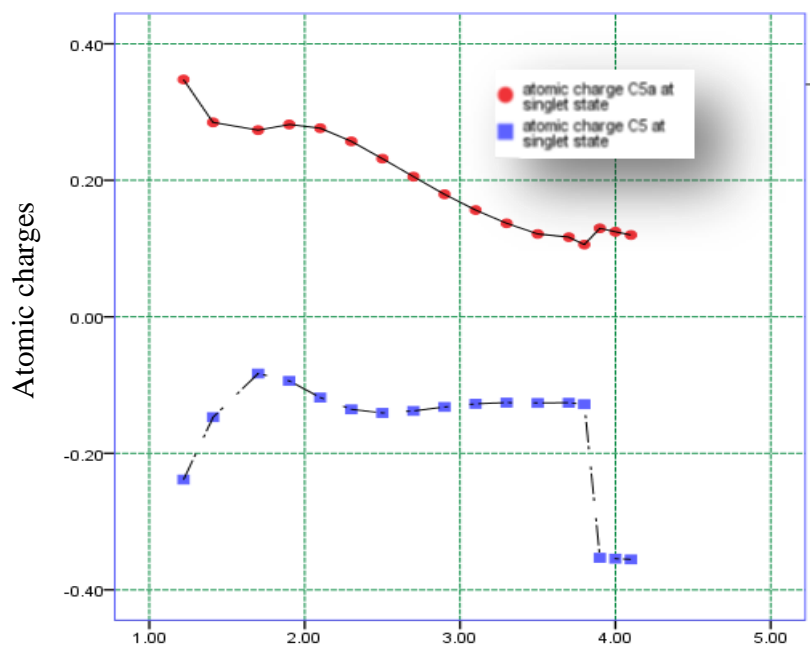

Fig (7): shows the atomic charges for C5a and C5 to acenaphthylene molecule at singlet state .

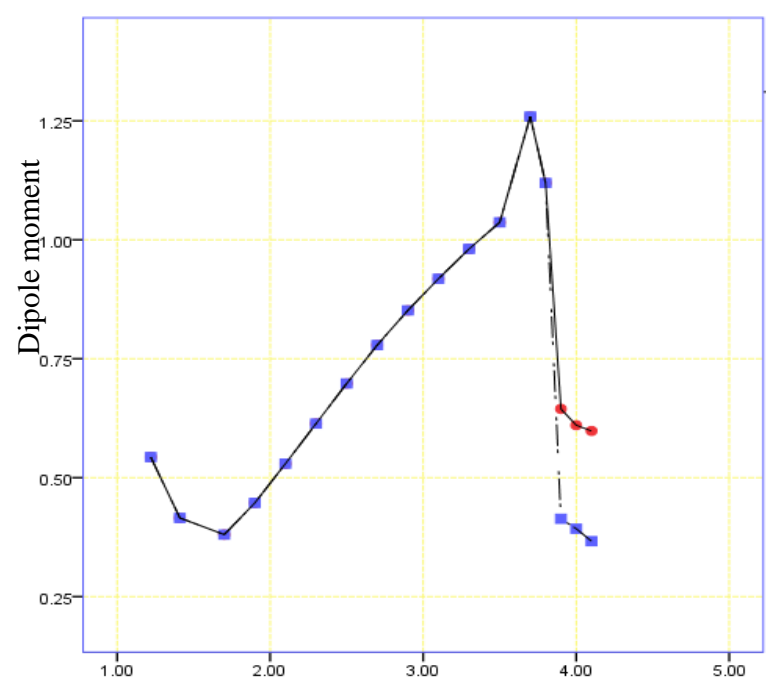

Fig (6): shows the dipole moment for C5a and C5 for acenaphthylene molecule .

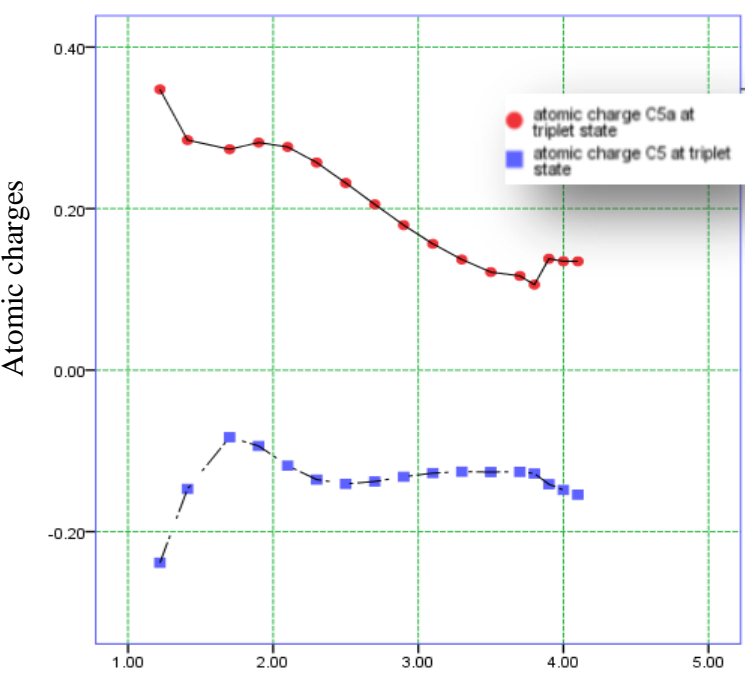

Fig (8): shows the atomic charges for C5a and C5 to acenaphthylene molecule at triplet state .

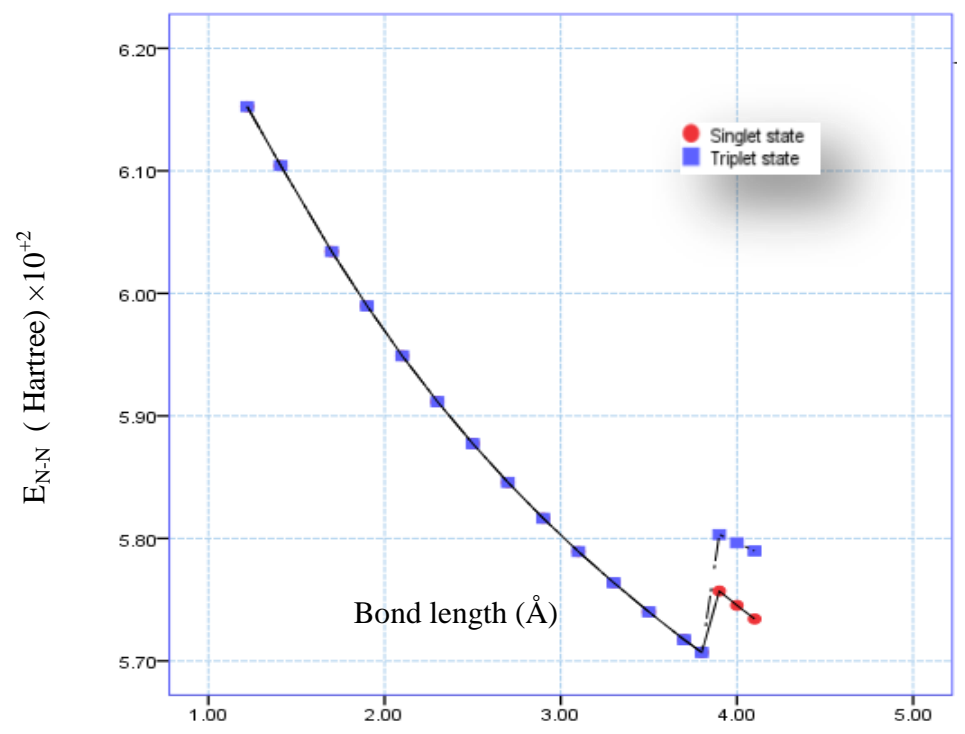

Fig (9): shows the $\mathrm{E}_{\mathrm{N}-\mathrm{N}}$ ( Hartree) for C5a and C5 for acenaphthylene molecule . 
Figure (10) illustrates the potential energy curve along with values for the activation energy and reaction energy for the cleavage of the $\mathrm{C} 5-\mathrm{C} 4$ bond in the triplet state. The pictorial representation (4) exhibits the transition state and the bond breaking product of $\mathrm{C} 5-\mathrm{C} 4$ and the atomic charges for each of the atoms by means of a coloured kev. In the transition state, the benzene ring is opened without the loss of the planarity. The change in electronic spin and the occurrence of rotation around the C5$\mathrm{C} 4$ bond axis is necessary to acquire the required stability for the molecular structure. Moreover , Figures(11-13) confirm the cleavage of the $\mathrm{C} 5-\mathrm{C} 4$ bond at the bond length $3.7 \AA$.

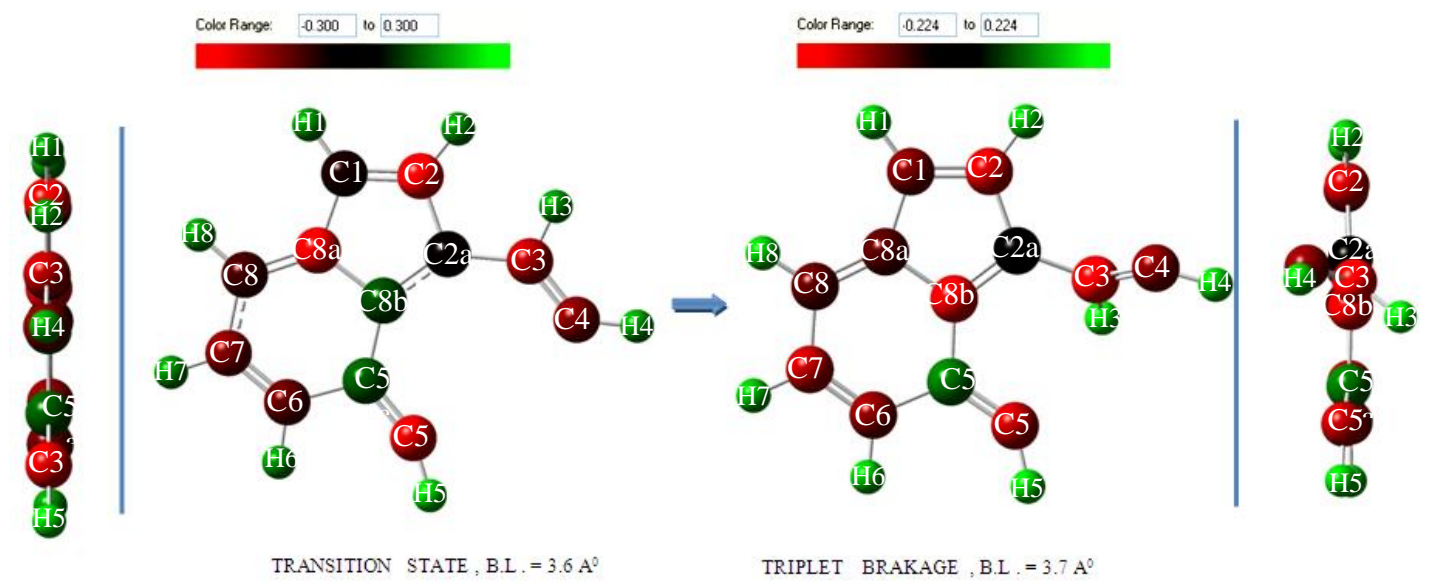

Scheme (4): exhibits the transition state, the product of the cleavage of the C5$\mathrm{C} 4$ bond, and the atomic charges for each the atoms (distinguished by means of colour) .

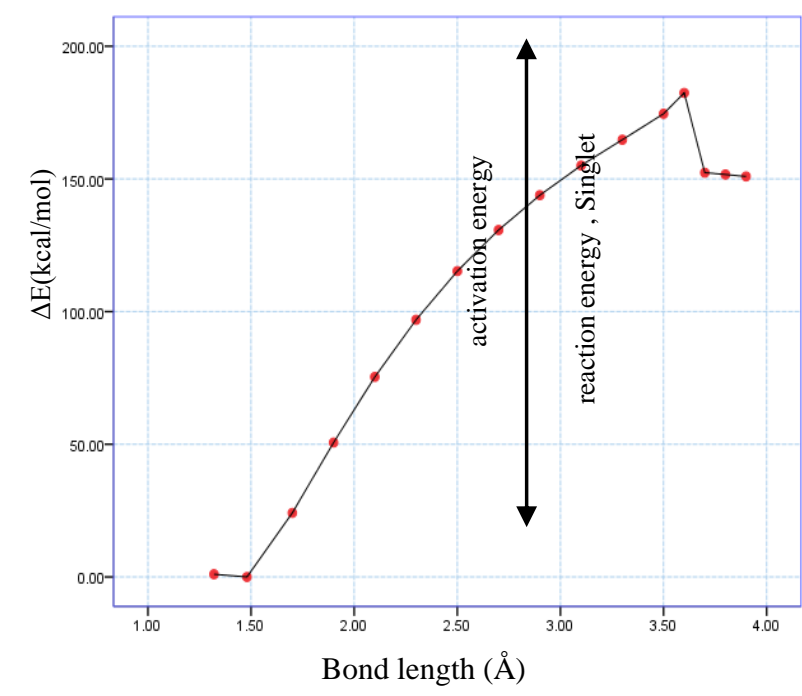

Fig (10): Shows the potential energy curve for acenaphthylene molecule for $\mathrm{C} 5-\mathrm{C} 4$ bond breakage .

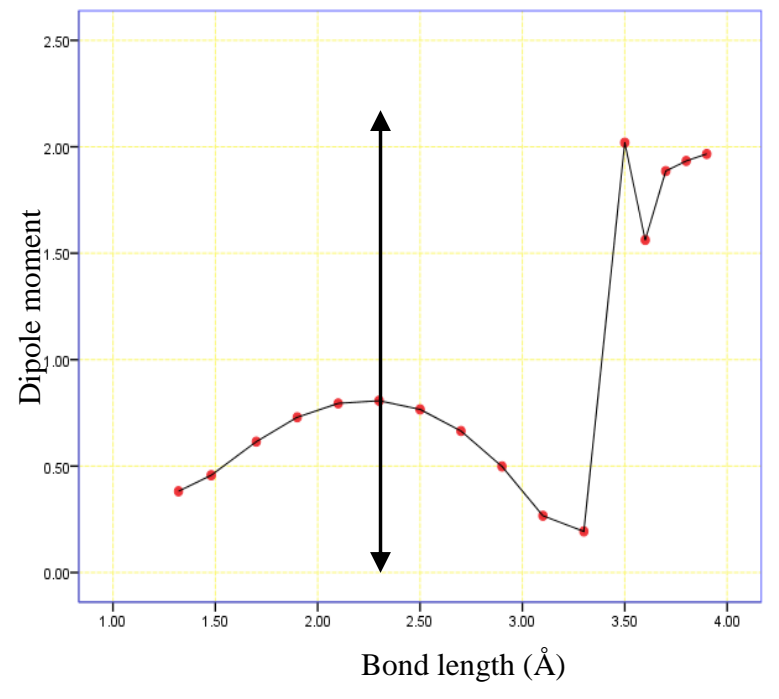

Fig (11): shows the dipole moment for $\mathrm{C} 5$ and $\mathrm{C} 4$ for acenaphthylene molecule . 


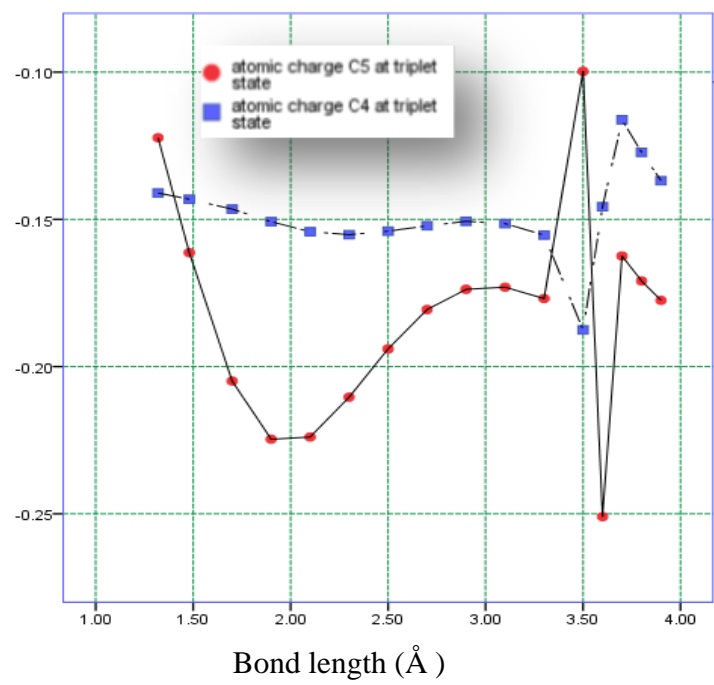

Fig(12): shows the atomic charges for C5 and C4 for acenaphthylene molecule

Figure (14) exhibits the values of the activation energy and the reaction energy by virtue of a triplet state pathway $(147.764 \mathrm{kCal} / \mathrm{mol})$ and $(117.808 \mathrm{kCal} / \mathrm{mol})$, respectively. The mechanism of the reaction that includes the transition state structure and the cleavage of the $\mathrm{C} 3-\mathrm{H} 3$ bond is best described by means of Scheme (5) . Firstly, in the transition state, the hydrogen atom (H5) is moved away from the molecule with deviation from the plane in the sense that the interaction is experienced unequally between the hydrogen atoms (H5) and (H6, H7),i.e., there is a difference in the atomic charges. However, at a bond length of $3.5 \AA$, the hydrogen

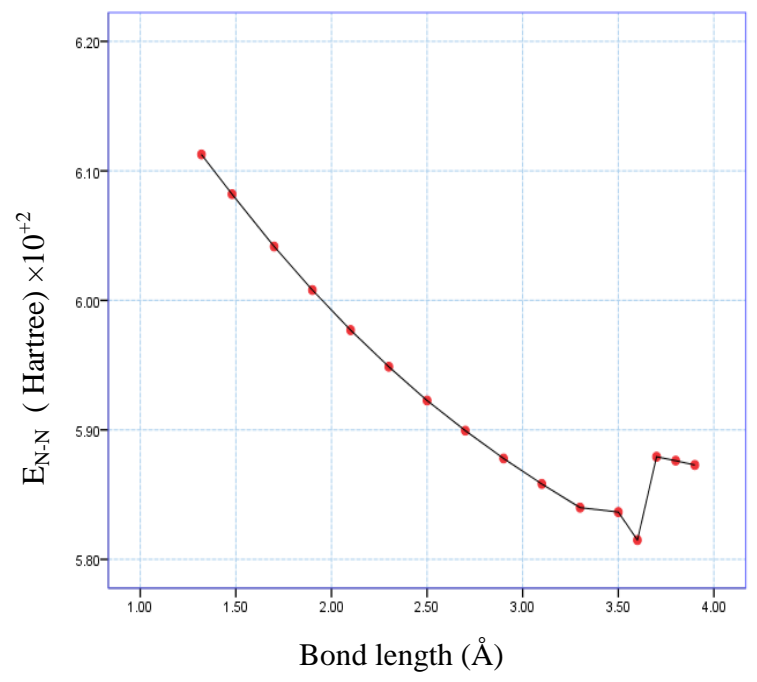

Fig (13): shows the $\mathrm{E}_{\mathrm{N}-\mathrm{N}}$ ( Hartree) for $\mathrm{C} 5$ and $\mathrm{C} 4$ for acenaphthylene molecule.

atom $\mathrm{H} 5$ is removed from the molecule as a free radical and moved far from the planar molecule. Both the structures preserve the planarity characteristic of aromatic compounds. The conversion of the atomic charges occurs for the carbon atom $\mathrm{C} 5$ and the hydrogen atom $\mathrm{H} 5$ from positive values into negative values and approaches zero that refers to the release of the hydrogen atom $\mathrm{H} 5$ as a free radical without any interactions with other atoms that have been exhibited in Figure (16) . Moreover, Figures (15-17) confirm the cleavage of the $\mathrm{C} 3-\mathrm{H} 3$ bond at the bond length mentioned earlier.

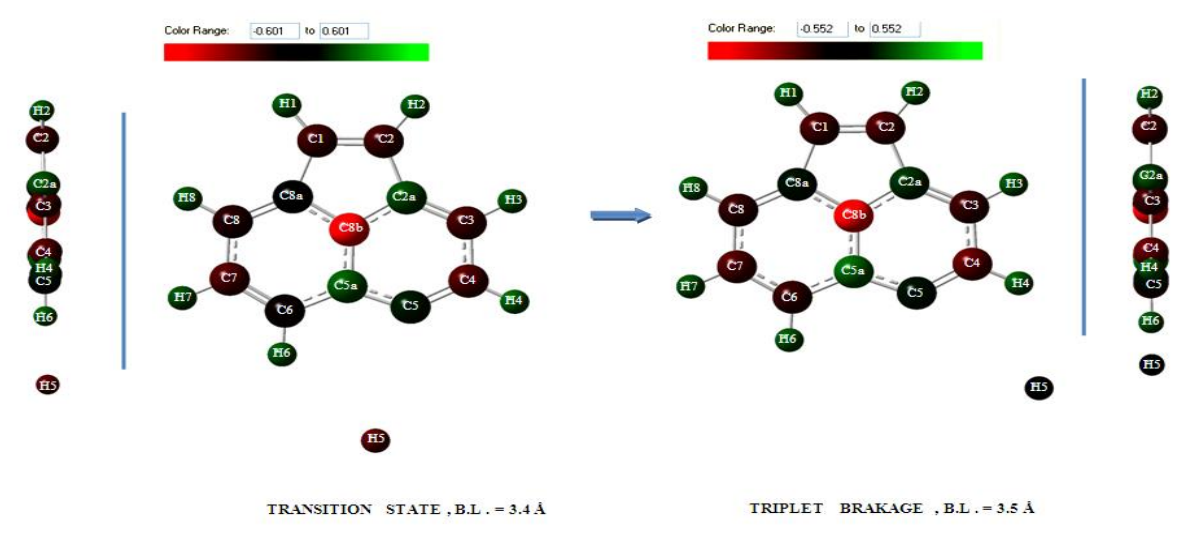

Scheme (5): exhibits the transition state, the product of the cleavage of the C3-H3 bond, and the atomic charges for each the atoms 


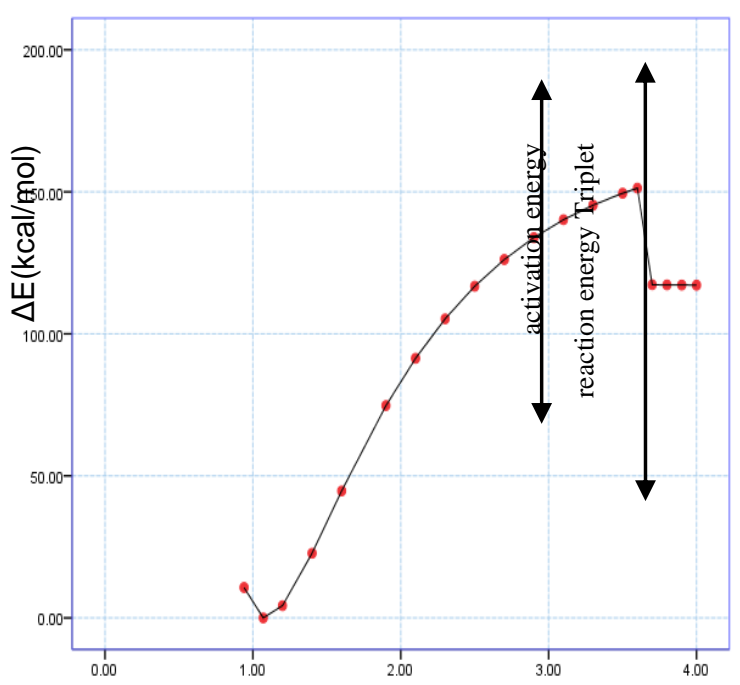

Fig(14): Shows the potential energy curve for acenaphthylene molecule for $\mathrm{C} 3-\mathrm{H} 3$ bond breakage .

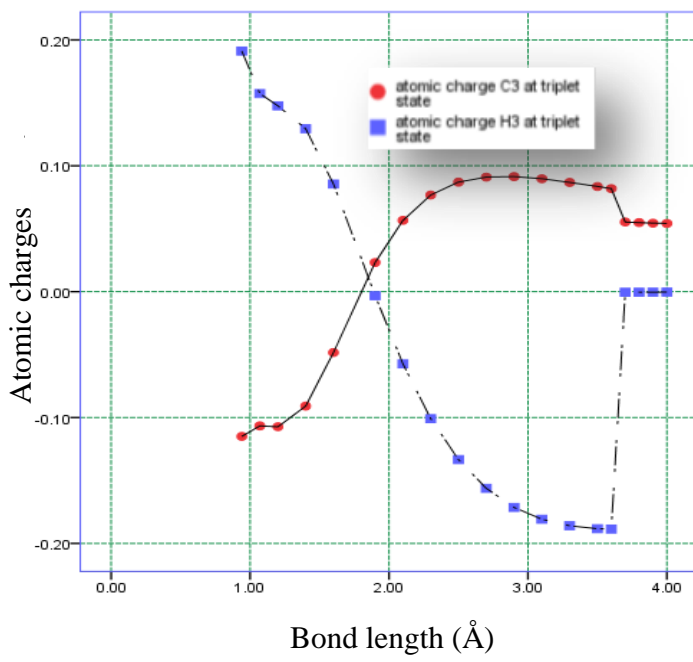

Fig (16): shows the atomic charges for C5 and H5 for acenaphthylene molecule.

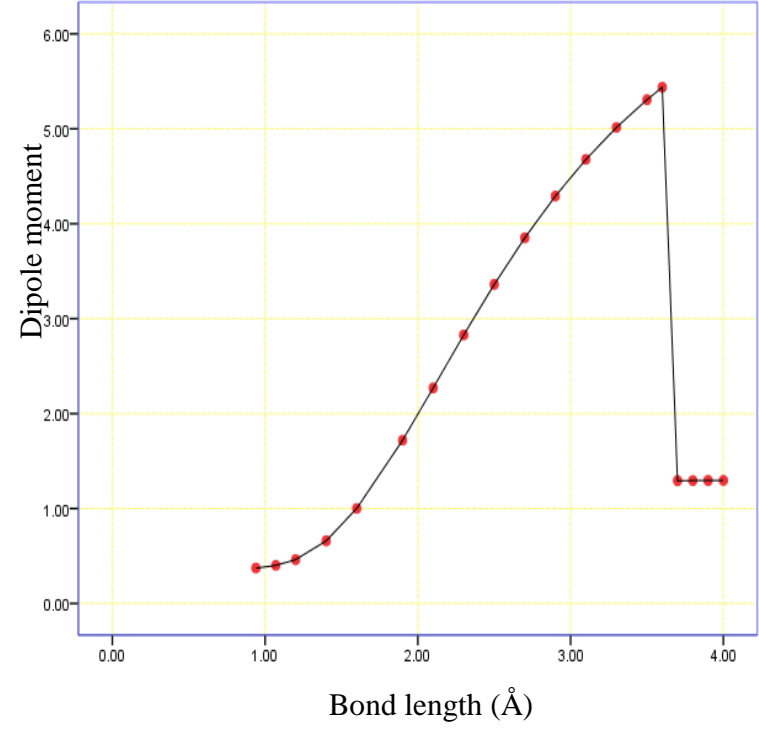

Fig(15): shows the dipole moment for C3 and $\mathrm{H} 3$ for acenaphthylene molecule

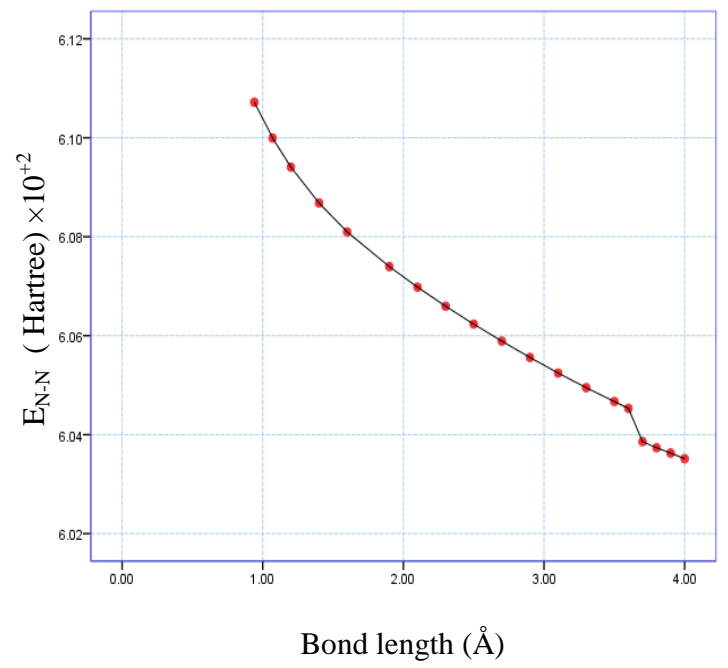

Fig (17): shows the $\mathrm{E}_{\mathrm{N}-\mathrm{N}}$ ( Hartree) for $\mathrm{C} 5$ and H5 for acenaphthylene molecule.

Table (2):Summary to values of energies as function to bond length

\begin{tabular}{|c|c|c|c|c|}
\hline Bond Type & $\begin{array}{c}\text { Activation Energy } \\
\text { Values } \\
(\mathrm{kCal} / \mathrm{mol})\end{array}$ & Bond Length $\AA$ & $\begin{array}{c}\text { Reaction Energy } \\
\text { Values } \\
(\mathrm{kCal} / \mathrm{mol})\end{array}$ & Bond Length $\AA$ \\
\hline C8b-C5a & 236.2514 & 3.6 & 192.7554 & 3.7 \\
\hline C5a-C5 & 164.2410 & 3.8 & $\begin{array}{c}120.1272 \text { singlet } \\
130.2414 \text { triplet }\end{array}$ & 3.9 \\
\hline C5-C4 & 182.4142 & 3.6 & 152.3400 & 3.7 \\
\hline C5-H5 & 147.7642 & 3.4 & 117.8083 & 3.5 \\
\hline
\end{tabular}

Table (2) exhibits the data of the present study for comparison purposes. The acenaphthylene molecule an appreciable dramatic change in geometry occurs when C8b-C5a, C5a$\mathrm{C} 5, \mathrm{C} 5-\mathrm{C} 4$ bonds are cleavage as compared with the $\mathrm{C} 5-\mathrm{H} 5$ bonds which is a slightly change occurs in geometry owing to the aryl radicals have a nominally singly occupied carbon $\mathrm{sp}^{2}$ orbital orthogonal to the $\pi$ electron system of the aromatic ring. 
Thus, the general tendency of such an orbital to acquire the maximum degree of $\pi$-character by the quasi-linear geometry ${ }^{(18)}$ about the carbon atom overcomes the ensuring increase in ring strain. Thus, the activation energies values are arranged in the following sequences : $\mathrm{C} 8 \mathrm{~b}-\mathrm{C5a}>\mathrm{C5}-\mathrm{C} 4>\mathrm{C} 5 \mathrm{a}-\mathrm{C} 5>\mathrm{C5}-\mathrm{H} 5$.

The low activation energy value for C5a-C5 bond due to the transition state is completely planar and reach full octet $^{(14)}$ and thus stabilizes the molecular structure. The low activation energy value for $\mathrm{C} 5-\mathrm{H} 5$ owing to the transitions state is coplanar and has the good variation for atomic charges via a bond length as the reaction proceeds. There are different mechanisms to describe the cleavage of the $\mathrm{C} 8 \mathrm{~b}-\mathrm{C5} \mathrm{a}>\mathrm{C5}-\mathrm{C} 4>\mathrm{C} 5 \mathrm{a}-\mathrm{C5}$ bonds as a result to different end products .

\section{References :}

1. Shanshal M and Muala M.M.,2011, Reaction paths and transition states of C-H bond rupture in aromatics , benzene and toluene. Jordan $\mathrm{J}$. Chem. 6:165-173.

2. Speright J.G. , 2007. The chemistry and Technology of petroleum. CRC press (Tayler \& Francis publications) Fourth Edition .

3. Gary J.H. and Handwelk GE., 2001. Petroleum Refining ,Technology and Economics. Marcel Dekker publications, Fourth Edition .

4. Smith M.B. and March J., 2007. March's advanced organic chemistry. Jonh Wiely publications , sixth Edition .

5. Luo Y.R. , 2007. Comprehensive handbook of chemical bond energies. CRC press (Tayler and Francis publications), First Edition.

6. Bausclicher C.W. and Langhoff S.R., 1998. Bond dissociation energy for substituted Polycyclic aromatic hydrocarbon and their cations. Molecular physics , 69 :471-476.

7. Kock W. and Hoitause M.C., 2001. A chemist's guide to Density Functional Theory. Wiely-VCH publications, second Edition.

8. Frisch M. J., Trucks, G. W. Schlegel H. B., Scuseria G. E. and co-worker. , 2009. Gaussian program. Inc., Wallingford CT, .

9. Sholl D.S. and Steckel JA., 2009. Density Functional Theory . John Wiely publications, First Edition .

10. Ramachandran K.I. and Deepa G. , 2008 . Computational chemistry and molecular modeling ; principles and application .Springer Publications , First Edition.

11. Bachrach S.M. 2007 . Computational organic chemistry . John wiely publications , First Edition.

12. Atkins P. and depaula J., 2009. Quanta , Matter, and Charges ; A molecular approach physical chemistry. Oxford press , First Edition.

13. Gokel G.W. , 2003. Dean's handbook of organic chemistry. McGraw and Hill press, second Edition.

14. Smith J.G. , 2011. Organic chemistry. McGraw and Hill press , Third Edition.

15. Hites R.A. and Simnsick W.J. 1987. Calculated molecular properties of polycyclic Aromatic hydrocarbons. Elseriver publications, First Edition. 


\title{
دراسة نظرية للتكسر الحراري لجزيئة الاسينفتلين
}

** قعطان عدنان يوسف

\author{
*ثنى عبل الجبار شنشيل \\ | ( جامعة بغداد / كلية العلوم / قسم الكيمياء \\ |جامعة القادسية / كلية العلوم / قسم الكيمياء
}

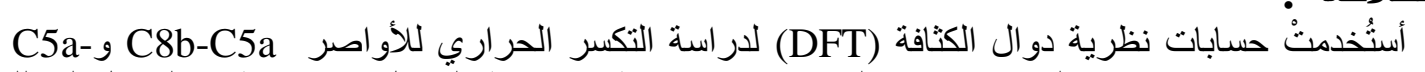

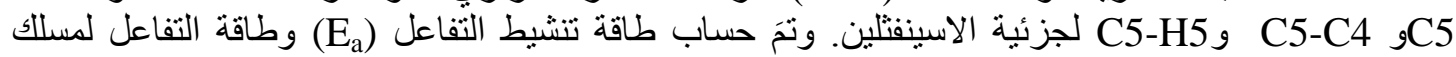
التفاعل (Er

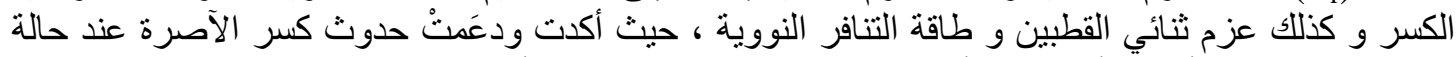

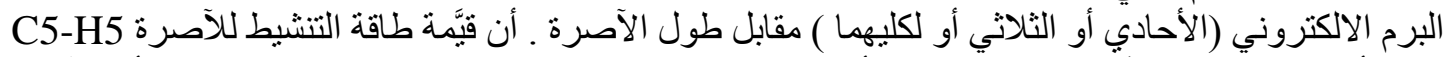

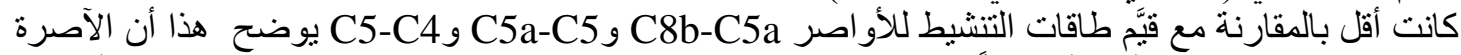

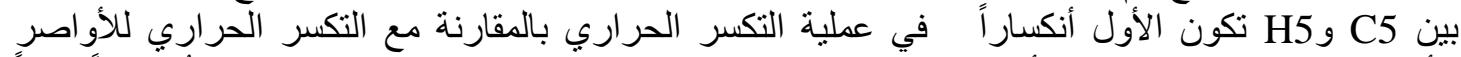

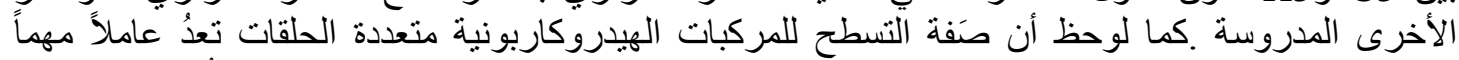

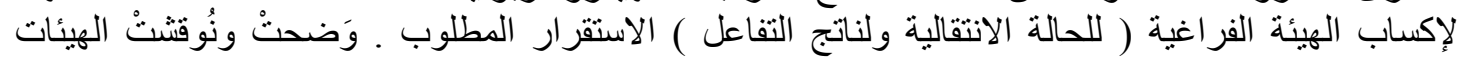

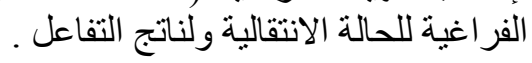

